Preprints of the

Max Planck Institute for

Research on Collective Goods

Bonn 2006/5

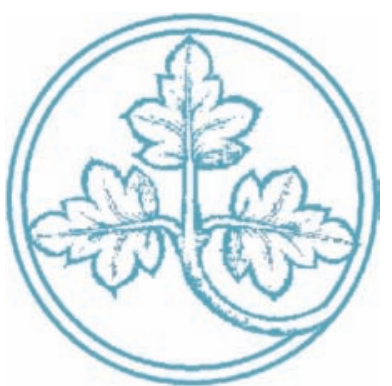

Netting of capacity in interconnector auctions

Felix Höffler / Tobias Wittmann

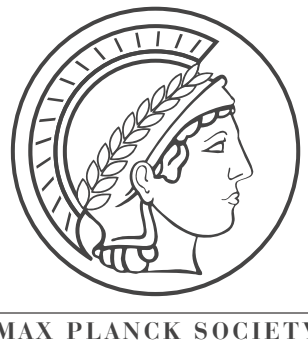




\title{
Netting of capacity in interconnector auctions
}

\author{
Felix Höffler / Tobias Wittmann
}

March 2006 


\title{
Netting of capacity in interconnector auctions*
}

\author{
Felix Höffler ${ }^{\dagger}$ and Tobias Wittmann ${ }^{\ddagger}$
}

March 1, 2006

\begin{abstract}
Scarce interconnector capacities are a severe obstacle to transregional competition and a unified market for electricity in the European Union. However, physically the interconnectors are rarely used up to capacity. This is due to the fact that the current allocation schemes make only limited use of the fact that currents in opposing directions cancel out. We propose a "netting" auction mechanism which makes use of this and in which even small transmission capacities can generate large competitive pressure in adjacent markets. Netting increases the usage of capacity and reduces the auctioneer's incentive to withhold capacity from the auction.

Keywords: Divisible good auctions, interconnector, electricity markets, competition policy

JEL-Classification: L94, D44
\end{abstract}

\footnotetext{
*We would like to thank Christoph Engel, Hendrik Hakenes, Martin Hellwig, Jörn Lüdemann and Karsten Neuhoff for helpful discussions. We are responsible for all remaining shortcomings.

${ }^{\dagger}$ Max Planck Institute for Research on Collective Goods. Kurt-Schumacher-Str. 10, 53113 Bonn, Germany. ++49(0)228 9141646. hoeffler@coll.mpg.de.

‡TU Berlin. Marchstr. 18. 10587 Berlin, Germany. ++49(0)30 31423280. wittmann@iet.tu-berlin.de.
} 


\section{Introduction}

The liberalization of energy markets has aimed to reduce entry barriers into regional and national markets. Important barriers are limited cross-border transmission capacities. The Council of European Energy Regulators (CEER) has named the "lack of transmission capacity (in particular, cross-border interconnection capacity)" first among the five major factors hindering the development of a single European energy market (CEER, 2003, par. 6).

Although interconnectors are regarded as congested, they are rarely physically used up to capacity. At the German-Danish interconnector between January 2004 and August 2005, the capacity was fully used only $18 \%$ of the time, although the price for capacity was positive the entire time. ${ }^{1}$ This is due to the way capacities are allocated, which makes only very limited use of the simple fact that flows in opposite directions physically cancel out. In this paper we propose a "netting" mechanism which takes this into account and can therefore increase the capacity made available for cross-border trade without building new capacities; it can do so just by better utilizing existing facilities.

With the creation of a single European market for electricity, the European Union has high ambitions. Since electricity can be transported at the high voltage level at very low cost, there could be trans-regional or trans-national electricity markets. A geographically large market, based on imports and exports of electricity, could increase the level of competition and increase efficiency by supplying electricity by the least-cost producer.

Electricity should, as far as possible, flow between Member States as easily as it currently flows within Member States. Improved cross border flows will increase the scope for real competition which will drive economic efficiency in the sector... (European Commission, 2004a, 3)

Connections between national grids are limited for historical reasons. "Transmission networks were not developed in order to support efficient trade", but rather to optimize intra-country operations (CEER, 2003, par. 8). With increasing interest in the international trade of electricity, cross-border transmission capacities have now become a bottleneck.

It has become common practice to allocate the scarce capacities in auctions in case of congestion. Although auctions improve the transparency of the capacity allocation, there are at least two problems. First, an auctioneer might have an incentive to withhold capacity from the auction process if this increases her auction revenues or protects her own downstream retail activities. Second, the auction formats currently used may fail to make efficient use of the capacities.

This can be illustrated by a simple example. Consider an interconnector of 20 Mega Watt (MW). In the currently used auction formats, $20 \mathrm{MW}$ will be

\footnotetext{
${ }^{1}$ We have confidential evidence that the German-Dutch interconnector, usually regarded as very congested, also is almost never used up to capacity. For instance, between May and August 2005, it was never physically fully used.
} 
offered in either direction. If demand in one direction were $100 \mathrm{MW}$ and in the other $80 \mathrm{MW}$, physically both could get served, but in the current system 80 MW and $60 \mathrm{MW}$ of the demand, respectively, remain unsatisfied. Even more, if $20 \mathrm{MW}$ are used in each direction, the interconnector would not be used at all! And indeed, in reality we observe (at least in long-term auctions) demand in two opposite directions, and interconnectors are often not fully physically used.

To use this idle capacity, we propose a "netting auction" and compare it to a stylized version of the currently used auction format. This is done in a simple two-stage game. In stage one, the auctioneer, who wants to maximize the auction proceeds, announces the capacity. In stage two $n$ bidders, with decreasing marginal valuation for capacity, take part in a divisible-good, uniform-price auction ("share auction"). To facilitate the analysis, we abstract from any uncertainty and asymmetric information, and, in order to be able to derive unique closed form solutions, we restrict bidders to linear bidding functions.

In this framework, we first analyze the current setup, where the auctioneer announces a capacity in each direction and the two separate auctions are held. This is compared to a "netting auction", where the auctioneer in stage one announces only the overall physical capacity of the interconnector. In stage two, bidders submit bid functions as before, but the "smaller" market (i.e. the market where aggregate demand at zero price is lower) will get served fully at zero cost. The "larger market" gets a quantity equal to the smaller market's maximum demand, plus the announced capacity. This overall capacity is allocated according to the rules of a uniform-price auction in the larger market.

The main findings are the following. First - and in line with standard double-marginalization arguments - for any quantity offered in the uniform price auction, the outcome is welfare inferior to monopolistic price setting. This is due to the well-known incentive for bidders to reduce their demand ("bid shading"). The auctioneer anticipates this and responds to it by a "supply reduction". Second, although (due to demand and supply reduction) the netting auction cannot achieve the first best either, it is welfare superior to having two separate auctions. The smaller market is served at a price of zero, hence bidders have no incentive to understate their true demand, and the efficient allocation is realized. Due to the netting, this provides a lower bound to the supply for the other market which the auctioneer cannot reduce. Therefore, she might be forced to offer more than the monopoly quantity to the other market. At best, she can offer the monopoly solution. Thus, bidders in the larger market cannot be worse off, while in the smaller they are strictly better off. The revenues of the auctioneer, however, are smaller.

Given these unambiguous theoretical results in favor of netting, we discuss possible obstacles to implementing it in practice. One important issue is that transmission rights currently are options to use capacity, not obligations. Netting, however, requires the compulsory usage of acquired transmission rights. By use of an example, we show that this does not necessarily imply that netting is impossible. It reduces the ex post flexibility of holders of transmission rights, but tends to increase overall efficiency.

The key concern of the paper - namely how to allocate congested resources 
- has been addressed in the literature on congestion management. Nodal pricing (Schweppe, Caramanis, Tabors, and Bohn (1988), Hogan (1992)) addresses the optimal pricing of transmission capacity. The regulation of such prices is analyzed in Vogelsang (2001) and Nasser (1997). A related literature discusses the incentives to expand congested networks. Joskow and Tirole (2003) provide an overview of this literature. None of this literature, however, focuses on auctions as an allocation mechanism or on the particular auction format used in the practice of interconnector auctions, which is the key contribution of our paper. When analyzing auctions, we rely on theoretical results on divisible-good auctions, in particular on Ausubel and Cramton (2002). Such "share auctions" were first analyzed by Wilson (1979). Kremer and Nyborg (2004) have more recently clarified important aspects of Wilson's approach with respect to the assumptions on the rationing rules.

In the more practical debate, Consentec and Frontier Economics (2004) have provided a detailed consulting paper to the European Commission, touching some of the issues of our paper. However, like most practical contributions, the approach assumes some bidding functions (which might or might not stem from truthful bidding) and discusses how different mechanisms would translate these bidding functions into allocations. This literature lacks a formal analysis of strategic bidding behavior (which would yield different behavior in different mechanisms). None of the existing literature explicitly focuses on the incorporation of the netting of counterflows into the auction process. We also add to the existing literature by combining an analysis of real world interconnector auctions with a theoretical treatment of strategic behavior of both sides of the market, the bidders and the seller.

The remainder of the paper is organized as follows. The next section describes the status quo of cross-border interconnection in the European Union. It points out the policy relevance and introduces the main characteristics (rules and results) of the currently held interconnector auctions. Section 3 shows, by a simple example, that indeed netting has the potential to increase competitive pressure and thereby to increase welfare, without having to invest in additional capacity. Section 4 provides the theoretical analysis of a netting mechanism and the main results of the paper. Section 5 discusses implementation issues in reality, and section 6 concludes.

\section{Status quo of cross-border trade in the Euro- pean Union}

\subsection{Competition Policy Issues}

Within the European Union, a clearly spelled out policy target is to establish a unified market for electricity:

At its meeting in Lisbon on 23 and 24 March 2000, the European Council called for rapid work to be undertaken to complete the in- 
Electricity Exports UCTE 1992 - 2004

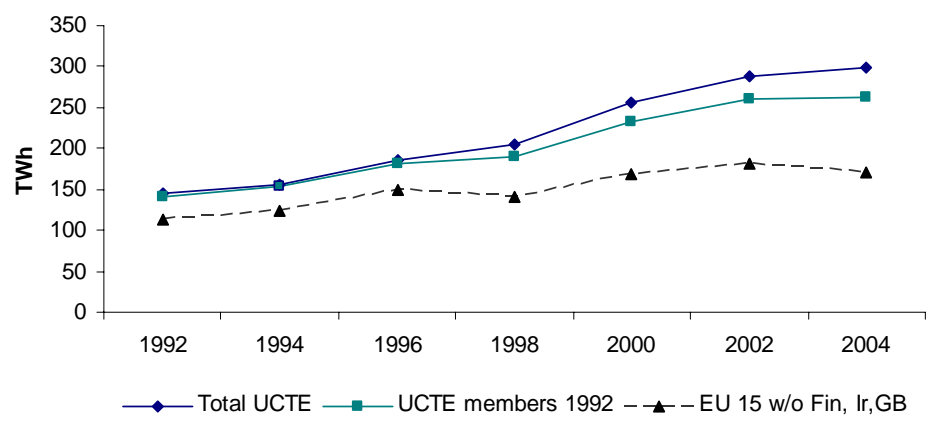

Figure 1: Electricity Exports, Source: UCTE

ternal market in both electricity and gas sectors and to speed up liberalization in these sectors with a view of achieving fully operational internal markets. (European Union (2003))

The increase in cross-border trade has, however, been limited so far. Figure 1 shows the (physical) export of electricity in TWh in the West and Central European area, covered by the UCTE (Union for the coordination of transmission of electricity). ${ }^{2}$ The Data indicate that cross-border activities have been increasing in continental Europe, but growth has been smaller in the EU-15 countries covered by the UCTE in 1992. The compound annual growth rate 1992 - 2004 has been $6.2 \%$ for the total UCTE (including additional member countries), $5.5 \%$ for the countries which were UCTE members in 1992, and $3.9 \%$ in the EU-15 countries. This figure is even more disappointing from the EU's perspective if one takes into account that the electricity consumption itself increased by $2.2 \%$ p.a. between 1992 and $2003 .^{3}$

The Commission has frequently called to remove the bottlenecks for crossborder trade, though with limited success:

The [EU] Commission has repeated called for rapid progress to be made on certain network investments, particularly those seeking to increase the integration of national electricity markets. ... Nevertheless results have been very disappointing up to now. (European Commission (2003))

\footnotetext{
${ }^{2}$ Data can be downloaded for each year on a monthly basis from: http://www.ucte.org/ statistics/ exchange/ e_default.asp. Data download for graph: 05/09/05.

${ }^{3}$ Consumption figures are published by Eurostat, downloadable at http://epp.eurostat. cec.eu.int, following the path "environment and energy - energy - energy consumption - final energy consumption of electricity". Data download: 05/09/05.
} 
Therefore, in its "TEN-E" program (Trans European Energy Networks), the EU Commission has identified additions to existing interconnector capacities as "priority projects" at almost every border between member countries (European Commission (2004b)).

With respect to the already existing interconnector capacities, which used to be allocated by the network owner in a rather opaque manner, it is now common practice to hold auctions for interconnector capacity when congestion occurs. A key question, however, remains: How much capacity is actually available?

To identify the capacity available, first, the maximum physical capacity is reduced by a security margin, which is set in such a way that it can still be operated in case of any single failure of the interconnector (referred to as $\mathrm{N}$ 1-security). Second, in interconnected networks, loop flows of currents arise. Those loop flows are predictable and additionally reduce the available capacity in one direction. Therefore, at some interconnectors, the amount of available capacity is direction dependant.

Since the network operator has superior information on these technological issues, she might be able to manipulate the result of these calculations. In particular, an integrated electricity company may want to withhold capacity from the auction process in order to make market entry into its home market more difficult.

This is at least a concern spelled out by the energy traders who want to engage in cross-country electricity trade. Their representation, the "European Federation of Energy Traders" (EFET), complains:

EFET believes that at nearly all regularly congested borders in the UCTE area potential NTC [Net Transfer Capacity], and therefore actual ATC [Available Transfer Capacity], are systematically underestimated. ... Among the reasons TSOs [Transmission System Operators] may do this are: ...

- Inaccurate or unduly conservative calculation of expected counter and loop flows; ...

- Non-objective approach to capacity reservations claimed by suppliers for legacy import / export contracts; ...

- Over-cautious withholding of capacity within a control area on one side of an interconnection, on the pretext of system security or balancing eventualities; ... (EFET, 2003, 2)

Therefore, an analysis of interconnector auctions should not take the capacity offered in an auction to be exogenous. It should rather investigate the incentives and opportunities for the auctioneer to manipulate the capacity. 


\subsection{Current System of Interconnector Capacity Alloca- tion}

\subsubsection{Rules}

The analysis focuses on the interconnector auctions between the UK and France, the Dutch-Belgian-German interconnector and the interconnector between Denmark and Germany. The rules are, however, similar in most other European interconnector auctions. ${ }^{4}$

Typically, transmission capacity is sold in three "tranches": an annual auction, a monthly auction, and a daily auction. In the annual auction, bidders can acquire a "band" for the coming year. That is, they receive the right to transmit a certain amount of Mega Watt (MW) for 24 hours, 365 days per year. The monthly auction sells a similar band for a certain month. In the daily auction, a day ahead, bidders can acquire a transmission capacity in MW for a specific hour, e.g. between 8 and 9 p.m., for the following day.

For each "tranche", the available physical capacity is offered in each direction in separate auctions. If 1,000 MW is the announced physical capacity, then 1,000 MW are offered in one direction and 1,000 in the opposite direction. ${ }^{5}$

All auctions are uniform-price auctions: each winning bidder pays the same price per MW, typically the price of the highest losing bid. Bidding functions are discrete (e.g. a maximum of 10 price-quantity combinations). This is a major difference from spot market auctions for electricity, where, e.g. at the European Electricity Exchange (EEX), bidders have to submit continuous bidding functions. Since bids are discrete, winning bidders may get rationed. The rationing rule is "pro rata on the margin". If rationing is required, because there is excess demand at the highest market clearing price, bidders with the highest demand at higher prices get served with priority (see Kremer and Nyborg (2004) for a theoretical analysis of the importance of the rationing rule).

Successful bidders of the annual and monthly auction can resell their capacity to other market participants. Furthermore, they can return it to the auctioneer, who will then include it in the next, shorter term auction, and the bidders will receive the auction proceeds for the returned capacity. What is sold in all auctions, also in the daily auctions, are options to transport electricity. Bidders are not obliged to use the capacity.

At some auctions there is some sort of netting. At the Danish-German interconnector, the auctioneer nets the nominated counterflows and supplies the difference on top of the physical capacity reserved for the daily auction. From Denmark to Germany, 400 MW of capacity are reserved for the daily auction. Winning bidders of the monthly and annual auction have to nominate (i.e. announce how much of their transmission right they will use) before the daily auction starts. Assume $400 \mathrm{MW}$ have been nominated from Denmark to Germany and 600 MW from Germany to Denmark. The difference of 200

\footnotetext{
${ }^{4}$ The Scandinavian (nordic) market uses a different (implicit auction) mechanism.

${ }^{5}$ Unless otherwise stated, we will use "capacity" as the capacity in principle available for trade, i.e. at the "N-1 secure level" and net of any loop flows.
} 
MW is then added to the supply of the short-term auction, i.e. the auctioneer announces that for the daily auction $600 \mathrm{MW}$ are available from Denmark to Germany. This differs from our approach to netting in that it takes place before the actual auction. However, it shows that netting causes no technological problems. Furthermore, from the data of the Danish-German auction, one can infer that there is actual demand for transmission capacity not only in the long-term auctions (which is discussed in the next section) but also in the daily auctions. For instance, in 2004, during $21 \%$ of the hours, capacity from the longterm auction in the direction Germany to Denmark was nominated (i.e. actually used), while in the daily auctions, there was a positive price for capacity in the opposite direction. The Appendix contains further institutional details.

\subsubsection{Auction Results}

We have seen that in interconnector auctions, usually only the physical capacity (after deductions for loop flows) is offered in both directions. Therefore, the physical capacity of the interconnector would be fully used, only if there were no trade in one direction.

When looking at the data of five of the major European interconnector auctions, it is obvious that this is not the case. There is trade in both directions in the annual and monthly auctions for all auctions considered here, namely capacity auctions between the UK and France, the Netherlands, Belgium, and Germany as well as between Germany and Denmark.

Table 1 shows the results of the annual auction 2005. Note first that the same amount is offered in both directions in all auctions, with the exception of the Danish-German auction (there is a considerable loop flow from South to North responsible for this asymmetry). The second important observation is that there are positive prices for both directions in all auctions. Prices, however, differ with respect to the direction. The data shows a strong demand for capacity towards the Netherlands. Prices paid in the opposite direction only range from $1.2 \%$ to $4.6 \%$ of the prices paid toward the Netherlands. Note, however, that even if prices differ significantly for each direction, a positive price still indicates that not all demand has been satisfied. Put differently, positive prices imply unsatisfied interest in trade in opposite directions which could provide the opportunity for netting the trades in order to achieve a higher utilization of the interconnector. Price differences are lower for the UK-France interconnector. At the Danish-German interconnector, prices are still different for each direction, but at the same order of magnitude.

The monthly auctions show similar results. Again, bidders pay for capacity in both directions, while prices differ in a similar pattern as in the annual auction for the respective directions. In contrast, in the daily auction there is trade only in one direction. The price for the other direction is zero most of the time.

Observation 1 In the long-term auctions, there is trade in both directions. In the daily auctions, there is trade only in one direction most of the time. 


\begin{tabular}{ll|l|l|r} 
From & To & $\begin{array}{l}\text { available } \\
\text { capacity } \\
{[\mathrm{MW}]}\end{array}$ & $\begin{array}{l}\text { obtained } \\
\text { capacity } \\
{[\mathrm{MW}]}\end{array}$ & Price \\
\hline Belgium & Netherlands & 328 & 328 & $18921.60 €$ \\
Netherlands & Belgium & 328 & 328 & $876.02 €$ \\
\hline Germany (RWE) & Netherlands & 356 & 356 & $51700.00 €$ \\
Netherlands & Germany (RWE) & 356 & 356 & $603.35 €$ \\
\hline Germany (E.ON) & Netherlands & 216 & 216 & $51868.01 €$ \\
Netherlands & Germany (E.ON) & 216 & 216 & $603.35 €$ \\
\hline Denmark & Germany (E.ON) & 350 & 350 & $27564.12 €$ \\
Germany (E.ON) & Denmark & 200 & 200 & $16655.00 €$ \\
\hline France & UK & 150 & 150 & $76375.00 €$ \\
UK & France & 150 & 150 & $4918.19 €$
\end{tabular}

Table 1: Results of the annual auction for 2005 at several European interconnectors

Potential reasons for demand in opposite directions in the long-term auction are long-term supply contracts. One reason for such cross-border contracts might be that incumbents typically loose market shares in their home countries. They try to outweigh this by acquiring customers in other countries, often by acquiring regional distribution companies or municipal utilities. Often the aim is to sell electricity from their own source to the customers of the acquired company, which provides an incentive for cross-border trade relatively independent from the spot market prices. ${ }^{6}$

We now turn to the question of the physical usage of the interconnectors. Although partial netting is sometimes used in short-term auctions, interconnectors are rarely used to full capacity. Data of the physical usage is often proprietary to the network operators and not publicly available. ${ }^{7}$ Fortunately, at the Danish-German interconnector, these data are available from Nordpool, the Scandinavian energy exchange. The net transfer capacity (NTC, the maximum capacity at the $N-1$ secure level and net of loop flows), the average physical usage, and the standard deviation are provided in Table 2 for the year 2004. Less than $50 \%$ of the physically available capacity was used on average. Figure 2 visualizes the usage of the interconnector between January 2004 and August 2005 on an hourly basis, measured by the utilization rate as the ratio

\footnotetext{
${ }^{6}$ Germany is a good example for this. EdF - the French electricity incumbent - has a large stake in EnBW, one of the four German electricity incumbents - and EdF has large power production facilities in France (In 2004, Germany imported $15.5 \mathrm{GWh}$, equivalent to $35 \%$ of total imports, from France). The state-owned Dutch Energy group Essent - also heavily active in power production - has stakes in many German electricity utilities via its majority shareholding in Stadtwerke Bremen AG. DONG, the Danish Gas, Oil, and Electricity group, has acquired Stadtwerke Lübeck, a German municipal utility.

${ }^{7}$ Integrated electricity companies which are faced with the complaint of withholding interconnector capacity clearly have no incentive to publish this information. There are, however, strong indications that, e.g., the Dutch-German interconnector is almost never used up to physical capacity, despite the high price paid for exports to the Netherlands.
} 


\begin{tabular}{ll|lll} 
from & to & $\begin{array}{l}\text { NTC } \\
{[\mathrm{MW}]}\end{array}$ & $\begin{array}{l}\text { average } \\
{[\mathrm{MW}]}\end{array}$ & $\begin{array}{l}\text { standard } \\
\text { deviation }\end{array}$ \\
\hline Denmark & Germany & 1200 & 590.4 & 507.2 \\
Germany & Denmark & 800 & 172.2 & 291.9
\end{tabular}

Table 2: Physical properties of the Danish - German interconnector

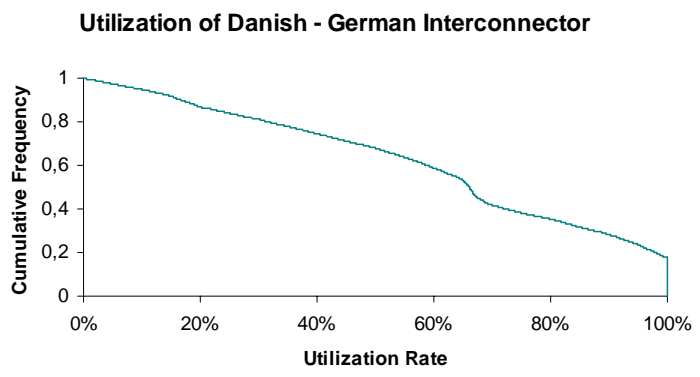

Figure 2: Utilization of Danish - German Interconnector. Source: NordPool

of the used capacity over the NTC. It shows that full usage of the capacity occurred only $18 \%$ of the time, while one-third of the time the physical usage was below $50 \%$ of the available capacity - although there was a positive price at these periods and therefore not all demand was satisfied.

Thus, we conclude that the current system leaves some interconnector capacity untapped.

Observation 2 Although prices are positive for at least one direction all the time, implying that some demand has not been satisfied, the interconnectors are rarely used up to capacity.

Although it is beyond the scope of the current paper to explain why this is the case, we briefly want to mention possible reasons for this. In the current system, in which capacities are options, there exists an incentive for the "hoarding" of capacity in the long-term auctions. One rationale might be hedging: firms want to have the option to trade if a positive price differential between two regions arises or if they acquire customers in the target region in the future. We will later discuss the option perspective in more detail. Alternatively, a firm might execute hoarding for strategic purposes. Blocking capacities can serve as a device for market foreclosure.

\section{How netting could work: An example}

Consider two similar countries, which differ slightly in market size. The demand for electricity is given for each of the two countries by the following linear 
demand functions:

$$
\begin{aligned}
& D_{1}\left(p_{1}\right)=100-p_{1} \\
& D_{2}\left(p_{2}\right)=98-p_{2} .
\end{aligned}
$$

There are two identical firms, one in each country. For simplicity, assume that both produce with the same constant marginal cost, which we normalize to zero. Initially, each national market is served by its incumbent, who acts as a monopolist. Therefore, in the absence of cross-country competition, the monopoly solution is realized in each country:

\begin{tabular}{l|ll} 
Monopoly Solution & Price & Consumption \\
\hline Country 1 & $p_{1}^{M}=50$ & $q_{1}^{M}=50$ \\
Country 2 & $p_{2}^{M}=49$ & $q_{2}^{M}=49$
\end{tabular}

Now assume that there exists a small interconnector between the two countries, with a capacity of two units per period. Using this interconnector, a firm can enter the adjacent market. Assume that, in line with the current system used in practice, only the physical capacity is sold in each direction. An entrant acts as a "fringe firm" in the market, and the incumbent optimizes against the residual demand function. Each firm dumps two units into the neighbor's market. To this, the incumbent reacts by reducing its own domestic supply:

\begin{tabular}{l|ll} 
Separate auction & Price & Consumption \\
\hline Country 1 & $p_{1}^{S}=49$ & $q_{1}^{S}=51$ \\
Country 2 & $p_{2}^{S}=48$ & $q_{2}^{S}=50$
\end{tabular}

There is some positive effect from cross-border competition. Since it is rather small, this might call for an extension of the physical capacity of the interconnector. Note that although there is some cross-border trade, the interconnector is physically not used, since each firm trades two units to the other market such that the flows exactly cancel out. Before calling for additional investments (which would indeed improve the situation), it might therefore be sensible, first, to investigate how the existing capacity might be used more effectively.

Imagine for a moment that there were no limits to the interconnector capacity and that the two markets could be considered as an integrated market. Assume that both firms would then act as a Cournot duopolist in the unified market; thus, the price would be the same in the two regions. This would yield the following outcome:

\begin{tabular}{l|ll} 
Netting mechanism & Price & Consumption \\
\hline Country 1 & $p_{1}^{C}=33$ & $q_{1}^{C}=67$ \\
Country 2 & $p_{2}^{C}=33$ & $q_{2}^{C}=65$
\end{tabular}

Each firm produces the same amount of 66 units. Note that to realize this far more competitive solution still only a physical transfer of 1 unit of electricity is necessary (from country 2 to country 1 ). The interconnector capacity could 
even be reduced - if only the interconnector capacity could be allocated in a netting mechanism such that the demands of the same size in opposite directions can cancel out.

This simple example shows that netting the demands for interconnector capacity could produce enormous welfare gains by increasing the competitive pressure in each market without increasing the physical transmission capacity. In contrast to markets where physical transportation in either direction is required (then firm 1 would have to transport 32.5 units into market 2 and firm 2 would have to transport 33.5 units into market 1 ), in electricity markets the laws of physics already imply a netting of transport quantities, since electricity can flow only in one direction.

\section{Analysis of Auction Formats}

The previous section has not taken auctions or strategic bidding into account (since there was only one buyer). In this section, we want to investigate competitive bidding environments and the effects of netting.

We proceed in three steps. First, we propose a simple theoretical framework in which we define a netting mechanism. Second, we analyze theoretically the properties of a netting mechanism compared to separate auctions in each direction. In this analysis, we allow for strategic behavior of both sides, the bidders' side and the auctioneer's side. Finally, we discuss possible practical issues with regard to the fact that any netting mechanism requires that capacities that have been acquired must be used and are not an option for transmission.

\subsection{Model}

To facilitate the theoretical analysis, we focus on a single (long-term) uniform price auction. There is no private information, no uncertainty, and there are no externalities. In equilibrium, a bidder who receives capacity will also want to use it.

Consider the following setup. There are two countries (indexed $C$ ), the $N$ orth and the South. In the North there are $n$ identical bidders, in the South $s$ identical bidders, with demand for transmission capacity into the other country. A bidder's demand for capacity is denoted by $q_{i}^{C}$, his marginal valuation by $v_{i}^{C}\left(q_{i}\right)$. The marginal valuation could correspond to the marginal profit, stemming from a given selling price in the downstream market minus an increasing marginal cost function. The payoff $\pi_{i}^{C}$ of a bidder who bought $q_{i}$ units at a (uniform) price of $p^{C}$ equals:

$$
\pi_{i}^{C}=\int_{0}^{q_{i}} v_{i}^{C}(x) d x-p^{C} q_{i}
$$

To enable closed form solutions, we restrict attention to linear marginal valuations:

$$
v_{i}^{N}=v_{i}^{S}=v_{i}=A-q_{i}, \quad A>0,
$$


implying

$$
\pi_{i}^{C}=\left(A-p^{C}\right) q_{i}-\frac{1}{2} q_{i}
$$

Hence, the two regions differ only with respect to the number of bidders, $n$ and $s$. Let the North be the market with the larger demand. For technical purposes, we assume that the difference between the markets is not too small:

$$
s, n \in \mathbb{N}, s>2, s<n-1 .
$$

Denote by $q^{N}$ the aggregate quantity of the North and by $q^{S}$ the aggregate quantity in the South. The auctioneer is interested only in auction proceeds. There is no cost for providing interconnector services (all infrastructure costs are sunk), thus the auctioneer's payoff equals:

$$
\Pi=p^{S} q^{S}+p^{N} q^{N} .
$$

Both countries are connected by an interconnector of size $\bar{K}$. This technological restriction requires:

$$
\left|q^{N}-q^{S}\right| \leq \bar{K}
$$

The first best in this environment requires that the smaller market is served up to its maximum demand, which is As. The North should get as much capacity as is technically feasible, which results from adding the maximum capacity $\bar{K}$ to the amount of the offsetting demand $A s$ :

$$
q_{F B}^{S}=A s, \quad q_{F B}^{N}=A s+\bar{K} .
$$

We compare two different auction rules, standard separate uniform price auctions for each market, and "netting auctions". For a comparison of the two auction formats, we take the total social surplus, measured as the sum of the players' payoffs:

$$
W=\sum_{i=1}^{n} \pi_{i}^{\text {North }}+\sum_{i=1}^{s} \pi_{i}^{\text {South }}+\Pi .
$$

In netting auctions, the auctioneer first announces the available net capacity $K \geq \underline{K} \geq 0$. The auctioneer can lie about the capacity, but there might be a lower bound $\underline{K}$, such that lower levels are not realistic. The bidders in both countries submit bidding functions $q_{i}(p)$, denoting the amount they are willing to buy at each price $p$. Bids are assumed to be continuous. ${ }^{8}$ The auctioneer then aggregates the demand function for each country to $q^{N}\left(p^{N}\right)$ and $q^{S}\left(p^{S}\right)$. She then compares the directions to see where the maximum demand is larger. Assume this is the North, i.e. $q^{N}(0)>q^{S}(0)$. In this case, bids from the South all get served at a price of zero, while the price for the North $p^{N}$ is the one that

\footnotetext{
${ }^{8}$ See the results of Kremer and Nyborg (2004) on the equivalence of continuous bidding functions (which is not current practice in interconnector auctions) and discrete bidding function in the presence of "pro rata on the margin" (which is current practice).
} 
equates demand to maximum supply, which is the sum of the physical capacity of the interconnector plus the maximum demand in the opposite direction:

$$
q\left(p^{N}\right)=K+q^{S}(0) .
$$

We compare this to standard, separate uniform-price auctions for each market. The auctioneer posts separate quantities $K^{N} \geq \underline{K} \geq 0$ and $K^{S} \geq \underline{K} \geq 0$ in the auction, where in equilibrium, (6) must be satisfied. Bidders submit bidding functions $q_{i}(p)$, and we denote the equilibrium outcome of the auction by $p^{N}$, the highest market clearing price in the North, and $p^{S}$, the highest market clearing price in the South.

That bidders use "demand functions" $q_{i}(p)$ (instead of degenerate bidding functions specifying only a price-quantity pair, or even only a quantity like in Cournot equilibria) can be motivated in different ways. First, in reality, bidders are sometimes forced to submit bidding functions with full support, like, for example, at the spot market at the European Electricity Exchange, EEX. Second, in the presence of uncertainty, e.g. about the capacity $K$ or the demand level $A$, demand functions are optimal, as shown in Klemperer and Meyer (1989) for the analogous case of supply functions in oligopoly. Third, for merely technical reasons, demand functions can be superior since they can help to avoid non-existence problems, e.g. like the Edgeworth existence problem, as has been noted by Grossman (1981).

\subsection{Equilibria}

We look for subgame perfect equilibria in the two stage game, where at stage one the auctioneer selects the capacity level, and bidders submit bids at stage two.

For stage two, we focus on linear equilibria of this subgame. This is, however, no restriction on the bidding strategy, since an equilibrium in which bidders use linear strategies always exists. A full characterization of all equilibria of the game is, nevertheless, difficult for multi-unit auctions. ${ }^{9}$ In his recent textbook on auction theory, Krishna summarizes:

...[For uniform-price auctions] a closed form expression for strategies is not available ... Calculating equilibrium strategies [is] a difficult task even in specific examples... (Krishna, 2002, 185)

The linear equilibrium, however, is unique (i.e. there is only one linear equilibrium), which facilitates the comparative statics with respect to the auction formats.

\footnotetext{
${ }^{9}$ In auction-theoretical terms, at the second stage, we have a (i) multi-unit uniform-price auction where (ii) bidders have valuations for more than one unit. The auction is a "share auction": bidders bid for a share of a perfectly divisible overall supply. Multi-unit auctions with downward sloping demand functions are analytically difficult, and few general results are available.
} 
Lemma 1 Consider a (separate) multi-unit auction with fixed supply of $\bar{K}$ and $m$ bidders. There exists a unique linear equilibrium with bidding functions of the form:

$$
q_{i}=\frac{m-1}{m-2}(A-p) \text {. }
$$

Proof. See Appendix.

This just reflects the general result that bidders employ "bid shading" in multi-unit auctions (see Ausubel and Cramton (2002)). Bidders can suppress the auction price by reducing their demand - as sellers do in Cournot competition when reducing supply in order to boost the selling price for their product. Therefore, bidders submit bidding functions that are strictly below their true demand functions, except for the first unit. If a buyer buys only one unit, there is nothing to be gained by reducing the price on inframarginal units, since there are none. Thus, the bidder behaves as in the second price auction by bidding the true value for the first unit. $^{10}$

The amount of bid shading depends on the number of competitors. If the number of competitors is small, there will be a lot of bid shading, i.e. the inverse demand function $p=A-q_{i}(m-1) /(m-2)$ will be much steeper than the marginal valuation function (2). However, if the number of competitors becomes large, $m \rightarrow \infty$, the influence of bidder $i$ on the auction price becomes small and hence the inverse demand function approaches the marginal valuation function.

Equipped with Lemma 1, we can now solve the full game. Let us start with the standard auction. Assume that the auctioneer can solve each market's problem independently. This will be the case if the technologically available capacity is not too small. The exact condition is provided in (13).

Given the bidders' behavior, the auctioneer will choose $K$ to maximize her profit $\Pi=K p(K)$. The optimal choice of $K$ is given by ( $I$ denotes the case of separate auctions, $m=s, n$ denotes the number of bidders):

$$
K_{I}^{C}=\frac{A}{2} \frac{m(m-2)}{m-1} .
$$

This implies a price of

$$
p_{I}^{C}=\frac{A}{2} .
$$

${ }^{10}$ To see why this is generally true, recall that a bidder's payoff equals

$$
\int_{0}^{q_{i}} v_{i}(x) d x-p q_{i}
$$

thus, a bidding function must satisfy the first order condition:

$$
p=v_{i}\left(q_{i}\right)-\frac{\partial p}{\partial q_{i}} q_{i} .
$$

Since higher demand for capacity $q_{i}$ leads to higher prices, $\partial p / \partial q_{i}>0$ and thus the bidding function is strictly below the true valuation $v_{i}\left(q_{i}\right)$, except for $q_{i}=0$. 
This outcome does not achieve the first best of (7). Furthermore, only by chance will it lead to full physical usage of the interconnector. This would be the case if

$$
\frac{A}{2} \frac{n(n-2)}{n-1}-\frac{A}{2} \frac{s(s-2)}{s-1}=\bar{K} .
$$

Treating each market independently is optimal if $K_{I}^{N}$ and $K_{I}^{S}$ are feasible, which requires:

$$
K_{I}^{N}-K_{I}^{S} \leq \bar{K}
$$

Before we compare this equilibrium of the separate auction to the netting mechanism, it is instructive to relate it to the monopoly solution. Consider a monopolist who knows the aggregate marginal demand functions, $Q^{C}\left(p^{C}\right)=$ $m\left(A-p^{C}\right)$. He would set the monopoly price $p_{M}^{C}=\frac{A}{2}$, and bidders would acquire in total an amount of $q_{M}^{C}=\frac{A m}{2}$. Comparing this to (11), we observe:

Proposition 1 Given (13) the quantity in the linear equilibrium will be lower in the auction than in the monopoly solution. Seller and buyers are better off under monopoly than under the uniform-price auction.

In our case, a multi-unit auction leads to a worse outcome for both sides. Put differently, replacing the auction by monopoly pricing leads to a Pareto improvement. The reason for the welfare loss of the auction is that it introduces a double marginalization problem. While in the monopoly solution only the seller has market power, in the auction the buyers also execute some market power via the bid shading.

Imposing a (standard) auction therefore is a two-edged sword. While it might have advantages because of increasing transparency or fair access, it may induce serious inefficiencies. It seems plausible that this effect is not an artefact of our linear example with symmetric bidders and no private information. That bidders use bid shading is one among the few general results for multi-unit auctions. It is also plausible that a seller will react to an aggregate bidding function which is below the true demand function by supply reduction. Thus, the double marginalization problem is likely to be a problem also for asymmetric bidders and private information. ${ }^{11}$

To achieve the monopoly solution, all the seller needs to know is the true aggregate demand function (she needs no information about the individual buyer's valuations). That, in particular in energy auctions, the seller has a good idea of the aggregate true demand function is quite plausible. Usually it is quite transparent which power plants are available in a country, at least on average. The spot market price is also public information. A seller therefore should have a good idea of the aggregate demand for transmission capacity also without

\footnotetext{
${ }^{11}$ With non-identical bidders and private information on types, multi-unit auctions have additional sources of inefficiencies. Due to bid shading, uniform auctions are inefficient in that they cannot guarantee that goods are allocated to the bidders with the highest valuations. Since bidders do not bid truthfully, marginal valuation among asymmetric bidders will in general differ in equilibrium, see e.g. Krishna (2002), Example 13.1.
} 
an auction, at least for long-term capacity allocation, which is the focus of our analysis.

We now turn back to the comparison of the two auction formats by analyzing the netting mechanism. Under the netting mechanism (for which solutions are indexed by $I I)$, the smaller market, i.e. the South, gets served for free up to its maximum demand, $p_{I I}^{S}=0$ and $q_{I I}^{S}=A s$. The northern bidders have to pay a positive price, which will never be above the price in the separate auction format. Since the northern quantity $q_{I I}^{N}$ will not be below the quantity in the separate auction, the netting mechanism is welfare superior: the amount of capacity used is larger, and therefore the social surplus higher.

Proposition 2 Comparing the unique subgame perfect equilibria with linear equilibria at stage two yields the following results: The netting auction is welfare superior to the separate auction format:

$$
\begin{aligned}
& q_{I I}^{N} \geq q_{I}^{N}, \\
& q_{I I}^{S}>q_{I}^{S}
\end{aligned}
$$

The profits of the auctioneer are lower in the netting mechanism: $\Pi_{I I}<\Pi_{I}$.

Proof. See Appendix.

With netting, the price will be zero in exactly one market. It cannot be zero in both markets due to the bidding competition. If it were, then the maximum demand in both markets must cancel out such that $q_{I I}^{N}+K=q_{I I}^{S}$. But then bidders in the North would still have some demand unsatisfied. If demand were left unsatisfied, a northern bidder could deviate, increase his bid, gain a higher capacity at a marginal price of $\varepsilon$ and be better off for $\varepsilon$ sufficiently small.

If the price is zero, there is no incentive to understate the true demand; thus, the southern bidders submit their true demand functions. They get served efficiently up to their maximum demand and are strictly better off than under the separate auction format. The maximum demand of the South supplies interconnector capacity for the North, which the auctioneer cannot influence. In particular, she cannot employ any supply reduction on this part of the supply for the northern bidders.

The only way to gain revenues is to offer some additional capacity on top of this. Therefore, the supply for the North will be strictly above the maximum demand of the South: $q_{I I}^{N}>q^{S}\left(p^{S}=0\right)$. Given that the bidders in the North know that their supply equals $K+q^{S}\left(p^{S}=0\right)$, they behave as if they were in a separate auction where the auctioneer offered $K^{N}=K+q^{S}\left(p^{S}=0\right)$. And since the auctioneer anticipates that the optimum behavior will result in (10), the maximum profit she can achieve is the profit when individually maximizing auction proceeds from the North, i.e. to realize the same solution as in the separate auction for the North. Thus, northern bidders can never be worse off under netting. They will be indifferent if the southern market is relatively small, since then $K_{I I}=K_{I}^{N}-A s$ (see Figure 3 ). They might even be better off if the the southern market is relatively large, i.e. the maximum southern demand is 
larger than the monopoly solution for the North, since then $q^{N}=A s+\underline{K}>K_{I}^{N}$ (where $\underline{K} \geq 0$ denotes the minimum capacity the auctioneer can propose), see Figure 4.

Since the quantity in at least one market is strictly higher than under the separate auction format, netting is welfare superior. The auctioneer still prefers the separate auction format since netting deprives her of revenues from the smaller market without offering improved profit levels for the larger market. However, the first best can still not be achieved for the northern market, where demand reduction and the auctioneer's response to it lead to inefficiently low capacity being traded. Nevertheless, we conclude from our analysis that the welfare advantage of netting over separate auctions seems to be robust against strategic behavior.

Since netting cannot achieve the first best, it will usually not lead to a full physical utilization of the capacity, measured against the true capacity $\bar{K}$. This will happen only if $K_{I}^{N}-A s=\bar{K}{ }^{12}$ It can even happen that if there is large scope for misreporting the true capacity, i.e. if $\underline{K}$ is very small, the physical capacity utilization will be lower under netting than under the separate auction format. However, in contrast to the separate auction, at least the announced capacity will always be fully used if there is a positive price, while in the separate auction, this will not be the case.

When changing unexpectedly from a separate auction format to a netting auction, the auctioneer will have an incentive to reduce the announcement of the physical capacity. If regulators impose that $K$ must be no less than $\max \left(K_{I}^{N}, K_{I}^{S}\right)$ in the auction, then the physical usage of the interconnector with respect to $\bar{K}$ will increase and the welfare improvement will even be larger. At the same time, auctioneers will more strictly oppose netting since this further deteriorates the auction proceeds.

\subsection{Discussion}

The big advantage of the current system without netting of transmission capacities is the low level of risk for both, the electricity supplier and the network operator, once transmission capacity is acquired by a market participant. An electricity supplier who has bought transmission capacity in the long-term (year or month) auction can be sure that this capacity is available. The network management does not have to be concerned that everybody uses her capacity, because even if one direction leaves all capacity unused, full physical delivery is still ensured in the opposite direction.

Typically, large supply contracts are long-term contracts. In principle, a supplier could first sign a supply contract, e.g. with a large industrial customer

\footnotetext{
${ }^{12}$ One could again compare the outcome to the monopoly outcome. Note that, contrary to the separate auction format, netting can do better than the monopoly solution. The southern market is always fully served, thus the result there is welfare superior to the monopoly solution. The result in the North will also be welfare superior if only the southern market is not too small: if $(n A / 2)<A s+\underline{K}$, then the monopoly quantity in the North is lower than the quantity in the netting mechanism.
} 


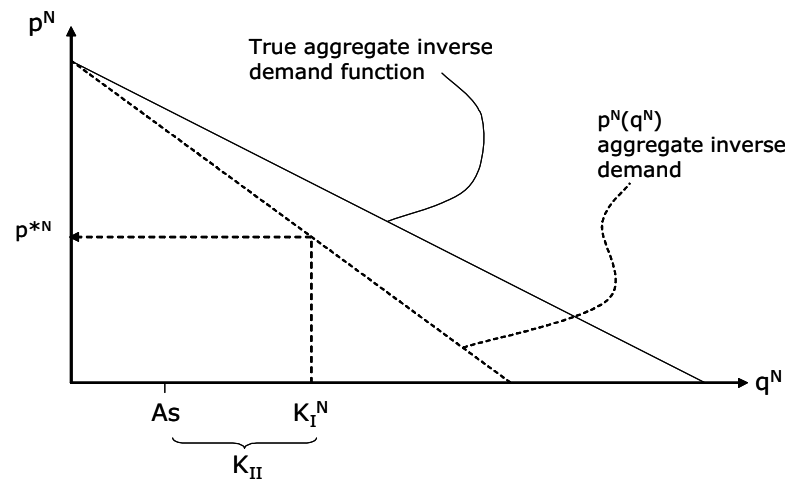

Figure 3: Northern market with netting of a small Southern market

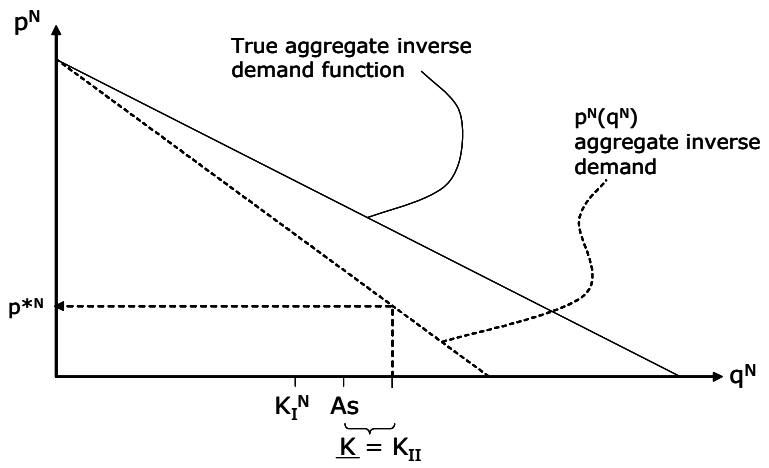

Figure 4: Northern market with netting a large Southern market 


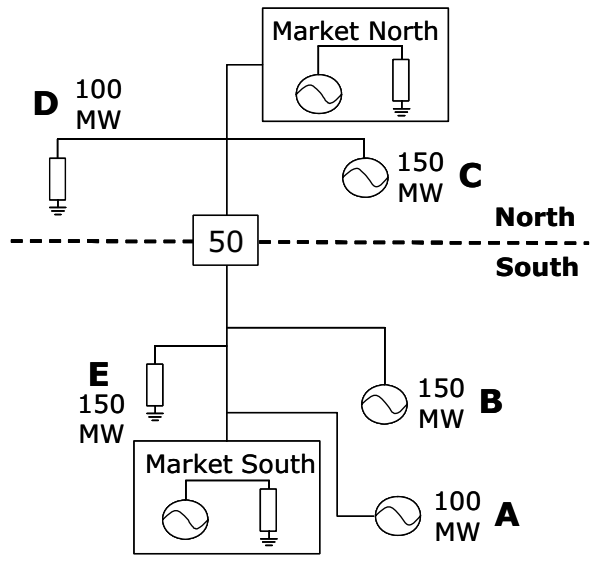

Figure 5: Example for cross-border trade

in a different country, and only afterwards acquire the transmission capacity required for delivery. This carries a significant risk, since if the supplier is not successful in the transmission capacity auction, she will not be able to fulfill her supply obligations. This would imply high penalties or payments for purchasing from alternative sources within the customer's country. Suppliers therefore tend to first buy relatively large amounts of transmission capacity, and afterwards to try to close contracts with customers, and then - potentially - return unused capacity.

With netting, matters are more complicated. Transmission capacities are "firm". Someone who has purchased capacity is obliged to physically use it. If a supplier first closes a supply contract and then buys capacity, she will still run the same risk as under the current system, namely the risk of not receiving capacity and thus of being unable to fulfill the supply obligation. If the supplier first buys capacity, she will run into the additional risk of getting no supply contract and thus being unable to fulfill the obligation to use the acquired transmission capacity. To illustrate the problem and its possible solutions, consider the following example, depicted in Figure 5.

There are two countries, the North and the South, connected with an interconnector of capacity 50 MW. Supplier $A$, situated in the South, has signed a contract with the northern customer $D$. The northern supplier $C$ hopes to get into a supply contract with the southern customer $E$, but has not yet closed it. Supplier $B$ is not yet active. This constellation would be technologically perfectly feasible. With a netting mechanism in the long-term auction, the suppliers could receive the transmission capacity required to fulfill their expected delivery obligations: 


\begin{tabular}{c|cc|c} 
Supplier & Capacity N $\rightarrow \mathrm{S}$ & Capacity $\mathrm{S} \rightarrow \mathrm{N}$ & $|(N \rightarrow S)-(S \rightarrow N)|$ \\
\hline$A$ & 150 & 100 & -100 \\
$C$ & 150 & 100 & 150 \\
\hline$\sum$ & & & 50
\end{tabular}

Now imagine that supplier $B$ becomes active and receives the supply contract with customer $E$. The northern supplier $C$ now has a problem: She must use the capacity from the North to the South of $150 M W$, acquired in the auction, but she has no customer in the South. If she were allowed to leave the capacity idle, supplier $A$ would no longer be able to fulfill her obligations towards customer $D$, although $A$ has acquired enough production capacity and transmission capacity. That situations like this can arise is the major drawback of firm transmission obligations, which are a prerequisite for a netting mechanism.

There are, however, solutions to this problem. Supplier $C$ has two alternatives. First, she can try to sell the transmission capacity of 150 from $N \rightarrow S$ on the short-term market for transmission capacity, since, in a netting mechanism, this is the same as buying the same amount from $S \rightarrow N$. If this is unsuccessful, $C$ still has a chance to fulfill her obligation to use the transmission capacity which she could not sell in the short-term auction by selling the production capacity of $150 \mathrm{MW}$ in the southern spot market for electricity. It then substitutes for southern production, which otherwise would have satisfied the southern demand expressed in the spot market with northern production. Only if this also fails will the network operator have to jump in and supply (negative) balancing energy in the South.

Although this argument suggests that there are no technological limitations that render netting impossible due to reductions in ex post flexibility, it points out a potential source of inefficiency. If, in our example, firm $C$ dumps its capacity in the southern spot market, it might crowd out more efficient producers in this market. This would be the case if the spot market price in the South reflected marginal production cost and firm $B$ 's production cost were higher. This inefficiency, however, could only be transitory, since firm $C$ would make losses, which cannot last forever.

\section{Conclusion}

Although transmission capacity is scarce and although this scarcity is regarded as a major obstacle to achieving more efficient market results, actual physical usage of the interconnectors is usually well below the physically available capacity. We propose a netting mechanism to improve the utilization of the available capacity. The effects are twofold. First, netting exploits the fact that counterflows are physically netted and that therefore each unit traded in one direction increases the available capacity in the opposite direction by one unit. In the netting mechanism proposed, this effect is exploited such that only that demand cannot be satisfied for which the difference of demands in both directions exceeds the physically available capacity. Thus, for any announced physical capacity, the utilization will be higher under netting than under the current system, in 
which two independent auctions are held, one in each direction. Second, we have shown that an auctioneer's incentive to announce low levels of capacity in order to maximize the auction proceeds is reduced under a netting mechanism. Thus, netting can support the increased cross-border trade of electricity without expanding the existing capacity (which might also be sensible).

In our theoretical analysis, we assumed that the auctioneer is interested only in the auction proceeds. This is sometimes not realistic. Frequently, the transmission system operator acting as an auctioneer is part of a vertically integrated electricity company. Such a company might have an interest in foreclosing the downstream market by providing low transmission capacities. Allowing for this would, however, even strengthen our argument: netting would also limit the scope for market foreclosure.

The current system provides high flexibility for traders to participate in the short-term spot market. It provides options for electricity transmission, which bidders in the spot market can use to support their offers in the electricity spot market. The price for this is that demand for long-term transmission capacity is often not satisfied, although it could be costlessly satisfied. Transmission capacities are often left unused. In contrast, netting maximizes the physical usage and increases the supply of long-term capacities at the cost of flexibility in bidding in the electricity spot market.

Further research could investigate optimum mechanisms with regard to this trade-off. One might think of hybrid auction systems where bidders can make two kinds of bids: firm bids and bids for transmission options. An allocation mechanism might then net the firm demands and afterwards serve the demand for transmission options if there is still capacity available. ${ }^{13}$ This might satisfy the need for flexibility in terms of options and at the same time improve the utilization of existing capacities.

\section{Appendix}

\subsection{Proof of Lemma 1}

We can drop the country indices since the argument is identical for both markets. We first show that a linear equilibrium always exists. Assume that the bidding strategy of all bidders $j \neq i$ is given by:

$$
q_{j}=a_{j}-b_{j} p .
$$

Since in equilibrium, $K=\sum_{j \neq i} q_{j}+q_{i}$, for bidder $i$ the impact on the equilibrium price is described by:

$$
p=\frac{\sum_{j \neq i} a_{j}-K+q_{i}}{\sum_{j \neq i} b_{j}} .
$$

${ }^{13}$ We are grateful to Karsten Neuhoff for suggesting this idea to us. 
He therefore maximizes:

$$
\left(A-\frac{\sum_{j \neq i} a_{j}-K+q_{i}}{\sum_{j \neq i} b_{j}}\right) q_{i}-\frac{1}{2} q_{i}^{2} .
$$

The first order conditions imply:

$$
q_{i}=b_{i}(A-p)
$$

where

$$
b_{i}=\frac{\sum_{j \neq i} b_{j}}{\sum_{j \neq i} b_{j}+1} .
$$

A vector $\left(b_{1}, \ldots, b_{m}\right)$ satisfying (14) constitutes a Nash equilibrium in bidding functions. This equilibrium is unique: (14) can be written as

$$
\left(1-b_{i}\right) \sum b_{j}=2 b_{i}-b_{i}^{2}
$$

Let

$$
\sum b_{j}=B
$$

which results in a quadratic equation for $q_{i}$,

$$
b_{i}^{2}-(2+B) b_{i}+B=0
$$

which has only one positive solution. Thus, all $b_{i}$ must be identical, implying $B=n b_{i}$. Using this, we find $b_{i}=\frac{n-2}{n-1}$ as the only non-negative solution as claimed in the Lemma. (The second solution, $b_{i}=0$ yields zero demand).

\subsection{Proof of Proposition 1}

The proof proceeds in three steps.

Claim 1 Bidders in the South submit their true valuation functions in equilibrium.

We prove the claim by contradiction. Either $q^{N} \leq q^{S}$; then at least one bidder in the North does not get his maximum quantity. He could then increase his bid (submit a less steep bidding function, i.e. choose a lower $b_{i}$ ). This is profitable and does not increase the price, since it nets the larger flows from the South to the North or uses some of the announced capacity, which is at least $K$. Or $q^{N}>q^{S}$; then bidders in the South can increase their bid without increasing the price and still get a quantity with positive marginal valuation.

Claim $2 q^{N}(0)-A s<K$ cannot occur in equilibrium.

If it $q^{N}(0)-A s<K$, at least one bidder in the North could increase his bid slightly, gain valuable capacity, and still leave the price unchanged at 0 .

Claim $3 q^{N}(0)-A s=K$ cannot occur in equilibrium. 
If this were the case, the price would still be zero, but an increase in bidding would trigger a positive price. However, the price increases only slightly, while the deviating bidder makes a discrete jump in the capacity allocated to him. Assume $q^{N}(0)-A s=K$ were an equilibrium. Then a bidder $i$ in the North receives, at a price of zero, the quantity

$$
q_{i}=\frac{A s+K}{n},
$$

implying a payoff of:

$$
\pi_{i}=\frac{A s+K}{n} A-\frac{1}{2}\left(\frac{A s+K}{n}\right)^{2}
$$

and she has chosen $b_{i}>1$ (if all choose $b_{i}=1$ then them maximum demand would be $\left.q^{N}(0)=A n>A s\right)$. Now consider a deviation to $b_{i}=1$. The bid function of the competing bidders would be:

$$
\beta_{j}=A-\frac{A n}{A s+K} q_{j}
$$

implying an aggregate demand function submitted to the auctioneer of:

$$
\widetilde{q}^{N}=\underbrace{(n-1) \frac{A s+K}{A n}(A-p)}_{\text {bids of other bidders }}+\underbrace{(A-p)}_{\text {bid of deviator }} .
$$

This must equal total supply of $A s+K$, implying:

$$
\widetilde{p}=A-(A s+K) \frac{n A}{(n-1)(A s+K)+n A} .
$$

Given this price resulting from deviation, we can now calculate the deviation profit $\tilde{\pi}_{i}$, which is larger than $\pi_{i}$ :

$$
\begin{aligned}
\widetilde{\pi}_{i} & =\frac{1}{2} \widetilde{q}_{i}^{2}=\frac{1}{2}\left(\frac{A s+K}{\frac{n-1}{n} \frac{A s+K}{A}+1}\right)^{2}>\frac{A s+K}{n} A-\frac{1}{2}\left(\frac{A s+K}{n}\right)^{2}=\pi_{i} \\
\frac{A}{n} & <\frac{1}{2}(A s+K) \underbrace{\frac{n-1}{\frac{n-1}{n} \frac{A s+K}{A}+2} \frac{A s+K}{A}+1}_{>1} \\
& \Leftarrow \frac{1}{2} A s+\frac{1}{2} K>\frac{A}{n} \\
A\left(\frac{n s}{2}-1\right)+\frac{n}{2} K & >0,
\end{aligned}
$$

which holds for $n, s>2$, as assumed in assumption 2. Thus, the deviation is always profitable, and the claim holds.

Since, due to claims 2 and 3 , in any equilibrium $q^{N}(0)-A s>K$, there will be a positive price in the auction for northern bidders. With a positive 
price, and given that southern bidders submit their true valuation, bidders in the North face a situation like that in a separate auction, where the capacity $A s+K$ is posted. We have already shown that in such an auction there is a unique symmetric equilibrium in which bidders submit functions according to (10), which we know is independent of the capacity offered. Bidders in the South receive their maximum payoff, thus they also have no incentive to deviate.

The optimal auctioneer's behavior still needs to be shown. Her profits are given by the following expression (where $p($.$) denotes the inverse demand func-$ tion resulting from the bids submitted by the bidders):

$$
\Pi_{I I}=\left(q_{I I}^{N}+K\right) \cdot p\left(q_{I I}^{N}+K\right) .
$$

Three cases are to be considered, depending on the size relation between the two markets.

(i) Small southern market: $A s<K_{I}^{N}-\underline{K}$. Then by setting $K_{I I}=K_{I}^{N}+A s$, the equilibrium quantity resulting from the auction will be $q_{I I}^{N}=K_{I}^{N}$, and the auctioneer's profit equals:

$$
\Pi_{I I}=q_{I}^{N} p_{I}^{N} .
$$

(ii) Large southern market: $K_{I}^{N}-A s \leq \underline{K}<q_{I I}^{N}(0)$. Now the auctioneer would need to set $K_{I I}<\underline{K}$ to achieve the same profit as before, $\Pi_{I I}=q_{I}^{N} p_{I}^{N}$. Since the auctioneer optimizes against a decreasing linear decreasing (inverse) demand function $p($.$) , profits are decreasing for q^{N}>q_{I}^{N}$; thus the profit maximum is given by the corner solution that results by choosing the minimum feasible level of $K: K_{I I}=\underline{K}$.

(iii) The case $A s \geq q_{I I}^{N}(0)$ cannot occur under assumption 2. To see this, note that

$$
\begin{aligned}
q_{I I}^{N}(p=0) & =\frac{(A-p)}{b_{i}}=(A-p) \frac{n(n-2)}{n-1}=A \frac{n(n-2)}{n-1} \\
A \frac{n(n-2)}{n-1} & >A s \\
s & <\frac{n(n-2)}{n-1},
\end{aligned}
$$

which is satisfied for $s \leq n-2$.

\subsection{Details of the Auction Rules}

All current systems take the maximum physical capacity of the interconnector as a starting point (minus loop flows in the network, which are estimated from historic data and cannot be influenced by the market participants). This is the maximum offered in each direction. An interconnector between the North and the South of size 1,000 MW will therefore offer 1,000 MW in the direction $N \rightarrow S$ and 1,000 MW in the opposite direction $S \rightarrow N$. Since the total capacity is sold in three tranches, auctioneers split the maximum capacity for each auction.

For instance, at the German-Danish border, the interconnector has a size of 1,200 MW. There is a technical loop flow of 400 MW from Germany to Denmark, 


\begin{tabular}{l|cccc}
{$[\mathrm{MW}]$} & Total NTC & Year Auction & Month Auction & Day Auction \\
\hline $\mathrm{DK} \rightarrow$ GER & 1200 & 350 & 450 & 400 \\
$\mathrm{GER} \rightarrow$ DK & 800 & 200 & 400 & 200
\end{tabular}

Table 3: Capacity reservation at the Danish-German interconnector

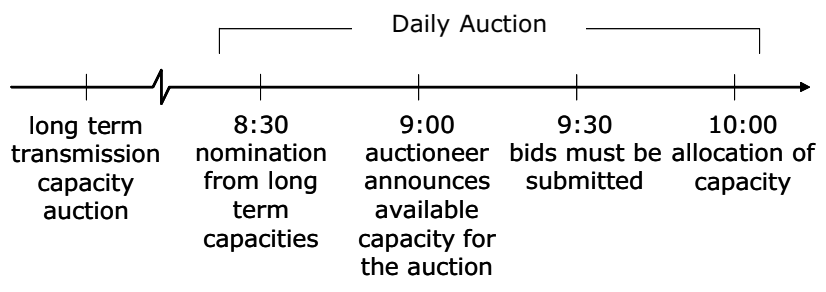

Figure 6: Timing in Daily Auction at the Danish - German Interconnector

thus the maximum amount offered is 1,200 from Denmark to Germany and 800 from Germany to Denmark. Out of these maximum capacities, the amount for each tranche is calculated; for example, from Denmark to Germany $350 \mathrm{MW}$ are sold in the annual auction, 450 in the monthly auction, and $400 \mathrm{MW}$ are reserved for the daily auction (see Table 3 ).

While no more than $350 \mathrm{MW}$ can be offered in the annual auction $D K \rightarrow$ $G E R$, in the daily auction, more than 400 can be offered by the auctioneer because owners of long-term capacity can return capacity they are not going to actually use. Figure 6 illustrates in detail the process of the daily auction for the Danish-German interconnector auction.

In the morning, each holder of capacity must "nominate" his capacity for the following day, i.e. he must say how much of his capacity he will actually use. This announcement is binding. If some of the capacity is not used, it is returned and included in the daily auction. Thus, if bidder $A$ has acquired 100 MW in the annual auction, but will not use it on April 17 from 4-8 a.m., he will nominate zero capacity for this time in the morning of April 16. The auctioneer will (if no other player returns capacity) then offer $500 \mathrm{MW}$ for 4-8 am on April 17 in the auction held in the morning of April 16.

If all capacity offered in the different auctions is sold in each direction, and this capacity would actually be nominated, the interconnector would not be used physically. The flows would totally cancel out. There are, however, occasions where the auctioneers already make use of netting in the daily auctions. Since they know after the nomination how much of the long-term capacity will be used in each direction, they add the nominated amount for one direction to the amount offered for the opposite direction in the daily auction. This is done at the German-Danish interconnector and explains why, on some days, the amount offered in the daily auction exceeds the physical capacity of the interconnector. 


\begin{tabular}{|c|c|c|}
\hline & Ger -> Den & Den -> Ger \\
\hline \multirow{3}{*}{$\begin{array}{l}\text { max. capacity } \\
\text { reserved for long term auctions } \\
\text { reserved for daily auction } \\
\end{array}$} & 800 & 1200 \\
\hline & 600 & 800 \\
\hline & 200 & 400 \\
\hline \multicolumn{3}{|l|}{ Assume: } \\
\hline nominated & 400 & 300 \\
\hline therefore: returned & 200 & 500 \\
\hline \multirow{5}{*}{$\begin{array}{l}\text { Results: } \\
\text { Offer in daily auction }\end{array}$} & & \\
\hline & 200 reserved & 400 reserved \\
\hline & 200 returned & 500 returned \\
\hline & 300 nomination in opposite direction & 400 nomination in opposite direction \\
\hline & 700 total & 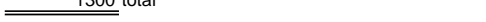 \\
\hline \multicolumn{3}{|l|}{ If price is positive Ger -> Den: } \\
\hline Usage of interconnector & \multicolumn{2}{|c|}{$\begin{array}{l}700 \text { if all capacity from daily auction is nominated } \\
\frac{100}{800} \text { net flow from long term nomination } \\
\text { total }\end{array}$} \\
\hline \multicolumn{3}{|l|}{ If price is positive Den -> Ger } \\
\hline Usage of interconnector & & $\begin{array}{l}1300 \text { if all capacity from daily auction is nominated } \\
\frac{-100}{1200} \text { net flow from long term nomination }\end{array}$ \\
\hline
\end{tabular}

Figure 7: Example of netting in the Danish-German interconnector auction

\subsection{Netting at the Danish-German interconnector}

At the Danish-German interconnector, the auctioneer, Eltra, uses a form of netting in the daily auction. The offer in the daily auction for each direction comes from three sources. First, from the capacity reserved ex ante for the daily auction. In 2004, this was $400 \mathrm{MW}$ from Denmark to Germany and 200 from Germany to Denmark. Second, all capacity from the long-term auctions that has not been nominated previous to the daily auction, is also added. Third, the amount nominated in the opposite direction is added. Figure 7 illustrates this mechanism. Note that this form of netting is not exactly the same as the one proposed in our paper. It takes place before the auction, thus any netting of demand for the opposite direction within the auction cannot be considered. Thus, the key issue of our paper, that netting in the long-term auction could improve the usage of capacity, remains valid even for the Danish-German interconnector.

If all capacity sold in the daily auction were used, then the interconnector would be fully used. However, since capacities in the daily auction are also options, not usage obligations, not all of this is actually used. Unused capacity can therefore be explained by the difference between the capacity acquired in the daily auction and the nomination of these capacities. This could happen, e.g. if an offer in the electricity spot market, which had been supported by a transmission capacity, was too expensive, such that it was above the market clearing price in the spot market auction.

Investigating the auction results provides further evidence that there is some long-term demand for transmission capacity independent of the spot market development. In 2004, we had 8,694 valid observations for the hourly prices for transmission capacity auction from Denmark to Germany. Of these 8,694 
observations, 6,726 observations $(77 \%)$ were "standard cases", where the sum of capacity offered in both directions equals $2,000(=800+1,200)$. Of these 6,726 cases, the capacity offered from Denmark to Germany exceeded the maximum capacity of 1,200 in 3,632 hours. Thus, there must have been nominations from the opposite direction (Germany to Denmark) from the long-term auction that were netted in the short-term auction in 3,632 cases. (Note that this is a lower bound: Netting could also occur in other cases if not all capacity from the longterm auction Denmark to Germany were returned. The offered capacity might be below 1,200, although netting happened). From these 3,632 cases, for which we know for sure that capacity has been nominated from Germany to Denmark, the price for capacity from Denmark to Germany was positive in 1,859 cases. Thus, in these 1,859 cases (or $21 \%$ of all of them), there was actual trade in both directions (otherwise the price would have been zero). This implies trade in the opposite direction at least $21 \%$ of the time and provides further evidence for the conjecture that there is an independent long-term demand for transmission capacity in opposite directions.

\section{References}

Ausubel, L. M., and P. Cramton (2002): "Demand Reduction and Inefficiency in Multi-Unit Auctions," Working Paper, University of Maryland.

CEER (2003): "Completing the Internal Energy Market: The Missing Steps," Press statement, October 2003, download under http://www.ceer-eu.org/.

Consentec And Frontier Economics (2004): "Analysis of Cross-Border Congestion Management Methods for the EU Internal Electricity Market," Study commissioned by the European Comission, June 2004.

$\begin{array}{ccccc}\text { EFET (2003): } & \text { "EFET Recommendation for } & \text { Objective } \\ \text { Quantificatio and Allocaion of Continental } & \text { European } \\ \text { Cross Border } & \text { Power Transmission Capacity," } & \text { download: } \\ \text { http://europa.eu.int/comm/energy/electricity/florence/10 } n . h t m . & \end{array}$

European Commission (2003): "Towards a Cometitve and Regulated European Electricity and Gas Market," Press release, October 2003, download under http://www.ceer-eu.org/ at 14/09/05.

(2004a): "Medium Term Vision for the Internal Electricity Market," DG Energy and Transport Working Paper, 01/03/2004.

(2004b): "TEN-E Priority Projects," published by the DG Energy and Transport, 10 June 2004.

European Union (2003): "Directive 2003/54/EC Concerning Common Rules for the Internal Market in Electricity and Reapealing Directive 96/92/EC," Official Journal of the European Union, L176/37. 
Grossman, S. J. (1981): "Nash Equilibriumm and the Industrial Organization of Markets with Large Fixed Costs," Econometrica, 49(5), 1149-1172.

Hogan, W. W. (1992): "Contract Networks for Electric Power Transmission," Journal of Regulatory Economics, 4, 211-242.

Joskow, P. L., And J. Tirole (2003): "Merchant Transmission Investment," NBER Working Paper, 9534.

Klemperer, P. D., And M. A. Meyer (1989): "Supply Function Equilibria in Oligopoly under Uncertainty," Econometrica, 57(6), 1243-1277.

Kremer, I., and K. G. Nyborg (2004): "Divisible-Good Auctions: The Role of Allocation Rules," RAND Journal of Economics, 35(1), 147-159.

Krishna, V. (2002): Auction Theory. Academic Press, San Diego.

Nasser, T.-O. (1997): "Imperfect Markets for Power: Competition and Residual Regulation in the Electricity Industry," Ph.D. thesis, MIT.

Schweppe, F., M. Caramanis, R. Tabors, and R. Bohn (1988): Spot Pricing of Electricity. Kluwer Academic Press, Norwell, MA.

Vogelsang, I. (2001): "Price Regulation for Independent Transmission Companies," Journal of Regulatory Economics, 20(2), 141-165.

Wilson, R. (1979): “Auctions of Shares," Quarterly Journal of Economics, 93(4), 675-89. 